\title{
Editorial
}

\section{Returning home when immigration fails: risk factors and the need for improved care}

\author{
Albina Balidemaj Basha ${ }^{1}$, Mark Small ${ }^{2}$ * \\ ${ }^{1}$ Rochester Institute of Technology, Prishtina, Republic of Kosovo \\ ${ }^{2}$ Clemson University, Institute on Family and Neighborhood Life, Clemson, South Carolina, USA
}

Migrating is stressful. Even under the best of circumstances, voluntarily moving from one's home country to another country requires careful consideration of several potentially stressful factors. A non-exhaustive list would include transportation, housing, finances, social support, language proficiency, and acculturation issues. In 2017, an estimated 68 million persons involuntarily migrated - 40 million internally displaced persons, 25 million refugees and 3 million asylum seekers (United Nations, 2017). Forcible displacement puts individuals and families at even greater risk of stress related to moving - as there is generally less time available for planning.

What happens when immigration fails, particularly for those who were forcibly displaced? The risk to well-being naturally increases, but the nature and extent is unknown. Most of the research attention has been given to the challenges faced during a migrant's outbound journey. To date, little attention has focused on the challenges faced when migrants are required to return home. This paper highlights some of the risk factors related to the journey home and the need for improved care.

\section{Where to go}

Sometimes a person is sent back to their county of origin or citizenship and sometimes back to the last transit country. Although precise numbers are difficult to obtain, the inflow of illegal immigrants in the European Union (EU) reached record levels during 2015 and remained high in 2016 (Frontex, 2009). Arrivals were mainly from Africa, the Middle East and Asia, many of whom turned to criminal networks of smugglers for assistance. Due to the illegal entrance, every year, between 400,000 and 500,000 foreign nationals are asked to leave the EU. However, only $40 \%$ of them are sent back to their country of origin or to the country from which they traveled to the EU. Lack of cooperation with the countries of origin remains one of the main reasons for a low rate of effective return among immigrants - even though the EU has "readmission agreements" in place which outline procedures and obligations for the authorities of the non-EU countries. An uncertain final destination is a risk factor for stress and anxiety.

\section{Deportation}

Deportation may compound psychological and physical health vulnerabilities that are already present - as returning migrants are likely to have faced discrimination, and health and educational challenges while immigrating. Deportation is often associated with few opportunities for interaction with medical or treatment services; including mental health testing, medical care, and substance abuse treatment (Brouwer et al., 2009). Additionally, because of the employment challenges and inability to fulfill the role of provider, as well as the stigma, shame, and depressive symptoms, many deportees may lose contact with supportive friends and family abroad. For female deportees, deportation also increases the risk of physical and sexual assaults (Robertson et al., 2012).

One study suggests trauma caused by deportation threatens mental health as much as the violence families experience in the countries they are fleeing. Researchers collected data on Post-Traumatic Stress Disorder (PTSD) symptoms, depression and anxiety symptoms and psychological well-being from 165 adult refugees from Afghanistan, Iraq, Syria and the African Great Lakes region. They also measured 27 different types of trauma exposure in the participants, such as fear for their lives, the destruction of their homes and being kidnapped. Two of the 27 types of trauma - family separation and physical assault, explained significant variance in all three measures of mental health after considering refugees' overall level of trauma exposure (Miller et al., 2018).

\section{What happens upon arrival}

Given the stress of the deportation process, returning migrants may be in a state of vulnerability at the very beginning of reintegration. Mental health studies suggest that re-assimilation, in the various forms it takes, can itself be a traumatic process rather than a simple solution to the traumas of deportation (von Werthern et al., 2018). Although not always the case, return migrants often face high levels of stigma after their return to their countries of origin as they are sometimes seen by their communities or their own families as failures and as criminals (Blanchard et al., 2011). They may also have to

\footnotetext{
* Author for correspondence: Mark Small, Clemson University, Institute on Family and Neighborhood Life, 321 Brackett Hall, Clemson, South Carolina, 29634, USA; e-mail: msmall@clemson.edu http://doi.org/10.32725/kont.2019.046

Submitted: 2019-08-22 • Accepted: 2019-09-11 • Prepublished online: 2019-09-17 
deal with the shame that deportation brings and threats that were the reason for immigration in the first place. In certain sociopolitical contexts such as the United States - where aggressive immigration enforcement affects many children of immigrants, additional support is needed to better serve families who may have been separated. Finally, unsuccessful migrants typically face employment and reintegration difficulties and often feel demoralized (Moulton, 2013).

The return of unsuccessful migrants may impact an entire community as it brings fear of family separation and distrust of anyone assumed to be associated with the government, including local police, school personnel, health professionals, and social service professionals (Green, 2019).

Upon arrival many find that the mental health support and treatment opportunities in the countries of origin are limited and expensive - or sometimes they do not exist at all. This is especially difficult for those suffering from PTSD, as symptoms may include triggers related to the original trauma and a lack of a perspective for the future.

\section{Risk factors during re-assimilation}

In order to improve success at re-assimilation, there are certain needs which should be considered when vulnerable migrants return to their country of origin.

\section{Social needs}

Return migrants may feel like immigrants in their own country as the poorest may feel an even greater level of detachment than they did prior to departure. Accordingly, emotional support is extremely important for the returnees, as they often risk tremendous amounts to make the journey and the return home may feel like a failure. Emotions often leap from relief at being back together with family to anxiety from realizing that they have returned to the life from which they walked away. Prioritizing reunion with family in the country of origin is extremely important, as family members will often help the returning migrant by providing shelter, food, and other types of support. However, re-integration with family and the society might not be straightforward, as the person might have changed, or the family may be critical of the person who left.

\section{Financial needs}

When migrants return, they will often be in a more vulnerable financial state than when they originally left. Typically, they will have spent a large amount of savings on the journey to the destination country and may not have been able to save. Additionally, they return to a country that many originally left for economic reasons. It is important that, on their return, they do not face similar economic pressures to leave and that income-generating opportunities be available.

\section{Medical needs}

Upon return, reintegration in the healthcare system, especially for children and the elderly is often listed as one of the most urgent needs for individuals and families. Returnees highlight that one of the main concerns in terms of medical needs is the normalization of the situation for their families and the need for institutional assistance for health problems (Brouwer et al., 2009).

\section{Education and language needs}

Respondents who have children say that they face problems with enrolling their children in kindergartens and schools, but also with the quality of education that is provided by these institutions (Zevulun et al., 2015). Migrating children and youth often need additional support to catch up on the months or years of missed education. They might also need to learn the language of their country of origin, or cultural customs. Finally, the returnees may need practical information on how to return safely and on what to expect upon return; to know their rights, and to ensure that these are respected during the journey and on arrival (Larrison et al., 2011).

\section{Next steps}

There is still much to be known about how best to facilitate the return of unsuccessful migrants to their home countries. What is known is that the process of immigrating is likely to be stressful and the unsuccessful migration only compounds the stress. Moreover, re-assimilation has unique challenges for those who return. Returning migrants often swap one set of stressors for another. As stressors present in exile (e.g., homesickness, inability to attain a work permit) become less important, new stressors (e.g., economic insecurity, being a stranger in their own country, confronting triggers of traumatic experiences) become more important. There is a prolonged period of stress. More research is needed on how best to reduce the stress of the deportation process and how best to mobilize resources to accommodate returnees.

For health care and social workers in all countries, steps can be taken to minimize the risk to the well-being of migrating families. In countries where deportation is prominent, addressing the mental and physical health needs of individual families, especially during deportation proceedings, can have both a preventative and therapeutic benefits. Similarly, heath care and social workers in countries receiving unsuccessful migrants might focus on special reintegration issues.

More than research or services, cultivating the political will to recognize this population as especially vulnerable is necessary. Migrant individuals and families, in whatever state of transition they appear, face increased risk factors that make them especially susceptible to psychological and physical harm. With 68 million on the move, we can do better to help them on their way or on their way back.

\section{References}

1. Blanchard S, Hamilton ER, Rodríguez N, Yoshioka H (2011). Shifting trends in central American migration: A demographic examination of increasing Honduran-U.S. immigration and deportation. The Latin Americanist 55(4): 61-84. DOI: 10.1111/j.1557-203X.2011. 01128.x

2. Brouwer KC, Lozada R, Cornelius WA, Firestone Cruz M, Magis-Rodríguez C, Zúñiga de Nuncio ML, Strathdee SA (2009). Deportation along the U. S.-Mexico border: Its relation to drug use patterns and accessing care. J Immigr Minor Health 11(1): 1-6. DOI: 10.1007/s10903-008-9119-5.

3. Frontex (2009). "The impact of the global economic crisis on illegal migration to the EU.” Warsaw: Frontex Risk Analysis Unit. [online] [cit. 2019-05-30]. Available from: http://www. europarl. europa.eu/meetdocs/2009_20

4. Green J (2019). Under the cloud of deportation threat: Testimonios reveal impact on mixed-status families. Hispanic Journal of Behavioral Sciences 41(2): 127-144. DOI: 10.1177/0739986319837205.

5. Larrison J, Murrugarra E, Sasin MJ (2011). Migration and poverty: Toward better opportunities for the poor. Washington, D.C: World Bank.

6. Miller A, Hess JM, Bybee D, Goodkind JR (2018). Understanding the mental health consequences of family separation for refugees: Implications for policy and practice. Am J Orthopsychiatry 88(1): 26-37. DOI: $10.1037 /$ ort0000272. 
7. Moulton AC (2013). David C. Brotherton and Luis Barrios, banished to the homeland: Dominican deportees and their stories of exile. New York: Columbia university press, 2011.

8. Robertson AM, Rangel MG, Lozada R, Vera A, Ojeda VD (2012). Male injection drug users try new drugs following U.S deportation to Tijuana, Mexico. Drug Alcohol Depend 120(1): 142-148. DOI: 10.1016/j.drugalcdep.2011.07.012.

9. Von Werthern M, Robjant K, Chui Z, Schon R, Ottisova L, Mason C, Katona C (2018). The impact of immigration detention on mental health: A systematic review. BMC Psychiatry 18(1): 382. DOI: 10.1186/s12888-018-1945-y).
10. United Nations, Department of Economic and Social Affairs, Population Division (2017). International Migration Report 2017: Highlights (ST/ESA/SER.A/404).

11. Zevulun D, Kalverboer ME, Zijlstra AE, Post WJ, Knorth EJ (2015). Returned migrant children in Kosovo and Albania: Assessing the quality of child-rearing from a non-western perspective. Cross-Cultural Research 49(5): 489-521. DOI: $10.1177 / 1069397115608173$. 